International Journal of Social Science and Economic Research

ISSN: 2455-8834

Volume:06, Issue:06 "June 2021"

\title{
SPACE AND EMOTION
}

Samdrisht Kaur, Bhavya Jain, Gunpreet Kaur, Muskan Malik, Ashi Chaudhary and Vibha Rewliya

Department of Architecture and Planning, Indira Gandhi Delhi Technical University for Women

DOI: 10.46609/IJSSER.2021.v06i06.020 URL: https://doi.org/10.46609/IJSSER.2021.v06i06.020

\section{ABSTRACT}

The study aims to review the emotional effects of different design elements on the human mind in orchestrated spaces. Spaces comprehend the volumetric aspect of a structure like different spaces within a building. These spaces are defined by the architectural design and elements used to generate a user experience in that space. This user experience is directly influenced by the emotions instilledin a person through these spaces.

Therefore, Spaces are evolved architecturally through design principles and elements that tend to provide the user with an experience of that space; that initiates an emotion within people. The study is specifically aimed to understand how design elements can be used by architects to create emotions by inhabitants of different orchestrated spaces within a residential space. The focus of the research is how a residence is used at different times of the day by different age groups? How are residents adapting/ responding to the changed functions of certain spaces in their homes due to the current COVID-19 pandemic?

Through literature studies, surveys, and case studies a link strong link between space and emotions is identified. The literature analysis shows the significance and relevance of the topic 'Space and emotions. The literature study tends to provide a range of scope that is prevalent to the topic; a deeper insight. Surveys give better knowledge and understanding of the issues, general perspectives, and highlight the limitations of the same. The case study will create a basis for all the previous studies that demonstrate how theoretical knowledge is implemented in different residential buildings.

The previous studies showcase which elements of design instill what emotions focusing on design elements and emotions primarily. Whereas the research penetrates deeper into the topic and analyzes how can our research topic "Space and Emotions" is put into practice and focuses on the emotional response to all aspects of design and spaces? 
The research will show how one can design spaces attuned to the concerns of a user which are primarily driven by emotions using design elements.

"We don't live in bungalows, duplexes, or flats. We live in our minds: Our permanent address."

\section{Introduction}

Buildings have a direct effect on our emotions. They can be depressing or uplifting, soothing or suppressing, welcoming, or forgiving. Architecture may affect a persons' health, behaviour, mood, decisions, and interaction with others.

Space encompasses the volume of a structure that is the parts of the building we move through gradually constructing our experience. Architectural designs are established by creating and carvingout space by dividing it using various elements like geometry, color, texture, and shapes.

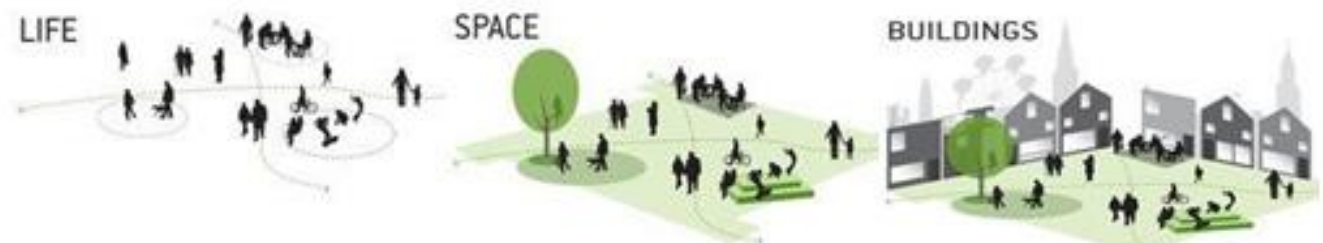

Figure 1. Life, space, and buildings

Architectural spaces have atmospheres that influence the emotional state of a person. It elicits different emotions in each one of us differently.

When architecture can connect emotionally with its occupants, its message and its meaning can be felt more deeply - thus, more readily leaving a lasting impression.

\subsection{TYPOLOGY: Residential}

Home is the space, we are most attached to emotionally, and during the pandemic, we are spending a lot of time in our home, and doing work from home. So it becomes the need of the hour, to do moreresearch, about what design aspects can be used, to make us feel more positive in our home.

\subsection{Research Questions}

In this research, we tried to find out how architectural spaces can be designed, attuned to the concerns of the user that cater emotional needs of all its occupants, and provide a better user experience. 


\section{International Journal of Social Science and Economic Research}

ISSN: 2455-8834

Volume:06, Issue:06 "June 2021"

- What are the basic architectural means that architects can use to design spaces attuned to theconcerns of a user?

- How does one home cater to the emotional needs of all its occupants?

- How to evoke emotions through design, so that the occupants have a deeper connection withtheir homes.

- How is our research topic "Space and Emotions" put into practice? Are architects able to useit as a good foundation for their design process?

\subsection{Aim}

To understand how design aspects can be used by architects to create emotions by inhabitants of different orchestrated spaces within a residential space.

\subsection{Objectives}

- To study the types of spaces, in a residence (Public-Private, Built-Open).

- To perceive the study of emotions and its types

- Explicating, the architectural elements and aspects like lines, form, shape, color, texture, light, scale, and proportion, that can be used to elicit emotions, and provide a better user experience.

- To study, how a residence caters to different sorts of needs and moods of various age groups present under one roof.

\subsection{Scope}

The scope of the study focuses to determine the interior and exterior spaces, particularly of a residence for the various design elements present in it. It includes the analysis of the deep impact created on the emotional state of a person in response to the design aspects of a space.

\subsection{Limitations}

Our study is limited to: -

- General impacts on people excluding exceptions

- Constraints on the quantity of survey data 
International Journal of Social Science and Economic Research

ISSN: 2455-8834

Volume:06, Issue:06 "June 2021"

- The boundation of the pandemic in the conduction of case studies.

\section{Literature Study}

\subsection{Space}

We construct a building, but the liveable inner area is the space!!

It gives form to an area creating boundaries with respect to various functions. Spaces can be divided into -built, unbuilt, and public-private spaces. Built space being a rigid form enclosed built mass whereas unbuilt space being a fluid form occupied by voids. Private spaces are areas we think are psychologically ours as opposed to open public spaces.

Spaces can evoke positive or negative emotions. If space has a high ceiling, organized elements, a view of nature, and natural light, it allows us to think freely. Whereas, if it is a tight space, lacks organization, has acute angles, or no connection with nature, it can distract our attention.

Humans are always situated in a space that bears the imprint of the spaces they have moved through.

The approach to design should be changed from Designer oriented design to a User-oriented design, that considers both functions of space and user's emotions. Spatial elements affect a person's health, behaviour, mood, decisions, and interactions with others. They can evoke certain emotions and can be used to recall the emotions of the past.

Spaces within a residence can be mainly classified as intimate, social, and personal spaces. Spaces like the bedroom, the toilet being the most intimate, followed by personal spaces like dining area, kitchen and social spaces like living area and front lawn.

\subsection{Emotions}

\section{The meaning of architecture can be deeply felt when one is emotionally connected to it.}

Emotions are the associations of thoughts, feelings, and behavioural responses that a person experiences with respect to the changes in the environment around them.

The role of emotions includes the evolution of consciousness and then the operation of the mentalprocesses.

Emotions involve various kinds of experiences and responses namely; subjective experience, a physiological response, and behavioural response. 


\section{International Journal of Social Science and Economic Research}

ISSN: 2455-8834

Volume:06, Issue:06 "June 2021"

- Subjective experience has an emotional and cognitive impact on the human experience.

- The physiological response is the automatic reaction that triggers a physical response to a stimulus.

- Behavioural response is evoked from underlying complex physiological changes that ariseconsequently from stress.
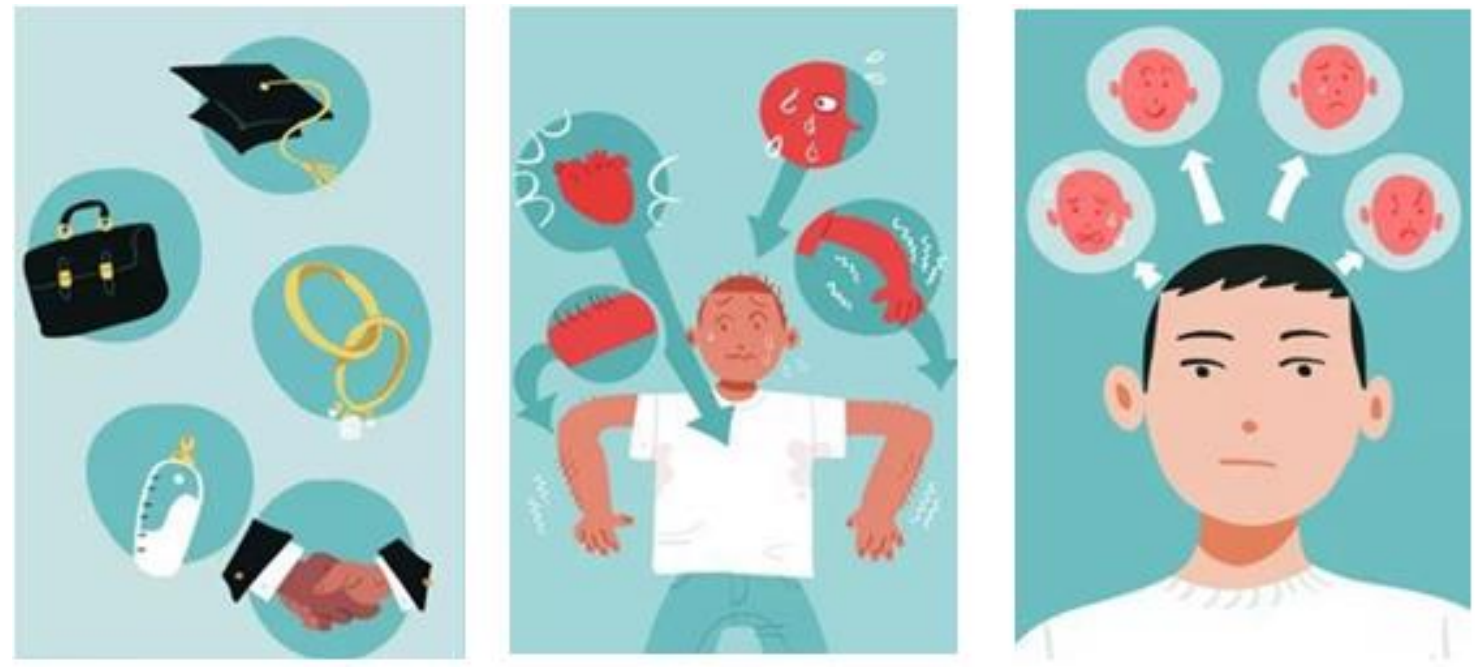

Figure 2. Subjective response, Physiological response and behavioural response

The basic human emotions like happiness, sadness, fear, anger, etc. can be combined to form complex emotions like joy, content, surprise, etc.

Another category of emotions is discrete and dimensional emotions.

The discrete emotions correspond to experiences, physiology, and behaviour and further show changes in the facial pattern and vocal expressions.

The dimensional emotions on the other hand are the emotions according to the position in space.

Spaces constituting a residence impact the inhabitants by the initiation of various emotions. Varied age groups feel discreetly in their homes depending on individual activities. Since there is the presence of the emotional quotient towards spaces, it makes it essential for the architects and designers to understand and further transform spaces according to the moods of the user.

\subsection{Design Aspects}

\subsubsection{Line:}


The aspects of line are often wont to draw attention faraway from or towards specific elements. Lines can be created using contrasting design elements (differing colors or textures) or through the definition of balance within a design. Horizontal lines create a calm and quiet sense whereas Vertical lines provide a sense of height. Diagonal lines strongly suggest movements and give a feeling of vitality to a picture and Curved lines appear to flow and are perceived to be in keeping with natural elements.

\subsubsection{Shapes:}

A neighbourhood that stands out from the space next to or around it by an outlined or implied boundary. Geometric shapes dominate our built environment as a majority of buildings are derived from them. Natural shapes consist of design shapes that replicate or imitate items found within ournatural environment.

\subsubsection{Form:}

The three-dimensional aspect of shapes. The building form has a major impact on the overall appearance and subsequent response to design. Geometrical Forms consist of primary building forms - cube, pyramid, and sphere and Natural Forms consist of forms that replicate our natural environment.

\subsubsection{Color:}

Different colors instil different feelings. Cool Colors like blue, violet tend to have a calming effect. They are cold, impersonal, antiseptic colors comforting, and nurturing in nature. On the other hand, represent excitement and sometimes anger. Warm colors convey emotions from simple optimism to strong violence. Neutral Colors of black, white, grey serve to unify diverse color palettes and often stand alone. Neutral colors are often cool or warm but are more subtle than blues and reds. Neutral colors help to place the main target on other colors or serve to tone down colors that may rather be otherwise be overpowering on their own.
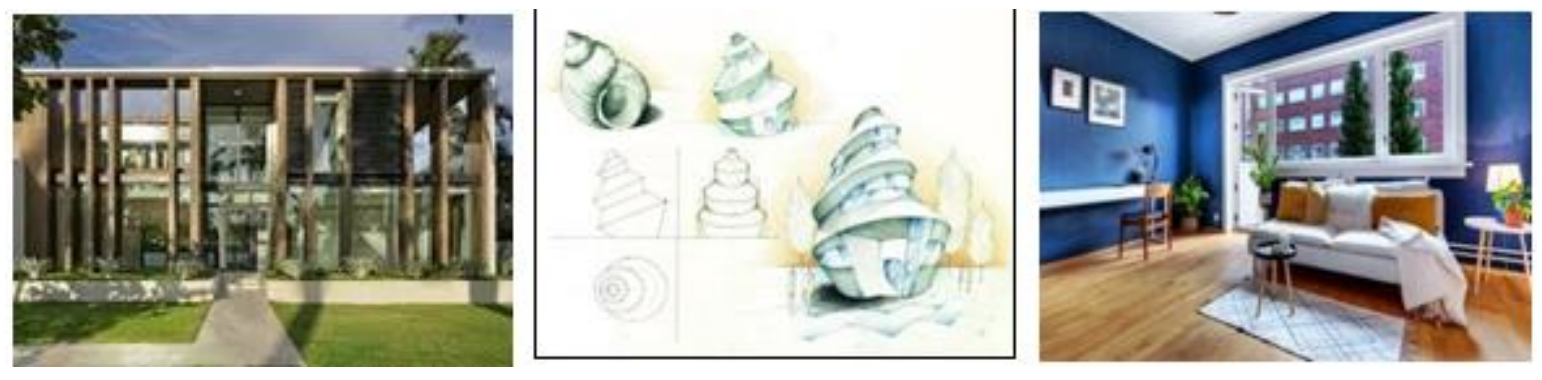

Figure 3,4,5. Design Elements: Line, Form, Colour 
International Journal of Social Science and Economic Research

ISSN: 2455-8834

Volume:06, Issue:06 "June 2021"

\subsubsection{Texture:}

Relates to the surface appearance of an item. It is perceived architecturally in two ways: visual and tactile. Smooth texture creates a cool, clean pristine appearance. Rough textures create a warm natural appearance; catching light to create a greater depth of field and presenting an increased visual weight over smooth textures.

\subsubsection{Light:}

Lighting is another important consideration when designing spaces to enhance the psychological health of the users. Sufficient lighting enables us to perform tasks easily, making us feel safer.

Lighting systems include artificial and natural.

Every room has its own unique and specific lighting needs. Every room has its range of minimumand maximum illumination levels which depend upon the aim and utility of an indoor space.

\subsubsection{Scale and Proportion:}

Scale and proportion articulate the design's aesthetics, structure, and functionality. Understanding scale and proportion help us to create a balanced indoor space.

The expression of proportion throughout a design is that the visual effect is created through the connection of volumes of space, also because of the balance of materials.
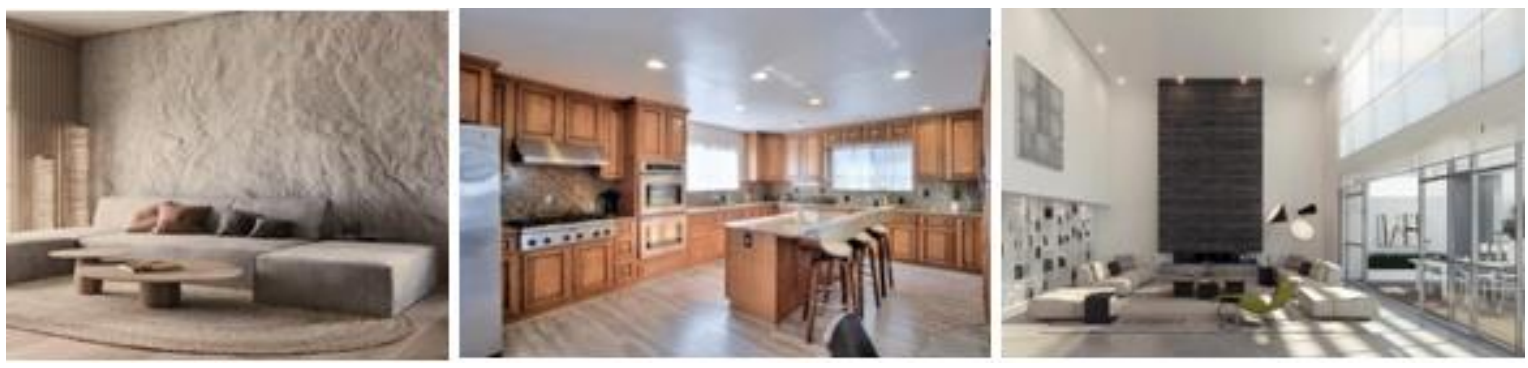

Figure 6,7,8. Design Elements: Texture, Light, Scale

\subsection{Summary of Literature Study}

To summarize the literature study, we found that spaces can be either public or private. Further, the residential spaces with the balance of built and unbuilt relationships can be divided into social, personal, and intimate spaces. 


\section{International Journal of Social Science and Economic Research}

Spaces elicit different emotions with respect to the design aspects present in them. There's an elementof care in the spaces that moves us which comes from this initiation of emotions.

A user-oriented design always incorporates the various design aspects namely:

Color - which is the visual stimulant that points out a particular emotion and heightens it. Light dimming of which relaxes the environment and brightening highlights space.

The texture and materials either enhance a sense of comfort or can excite impatience.

Shape and form, when geometric show harmony and stability and whereas natural ones are morewelcoming.

The function of the space plays a vital aspect so the lay-outing is a well-considered factor to fit theuser's emotional needs.

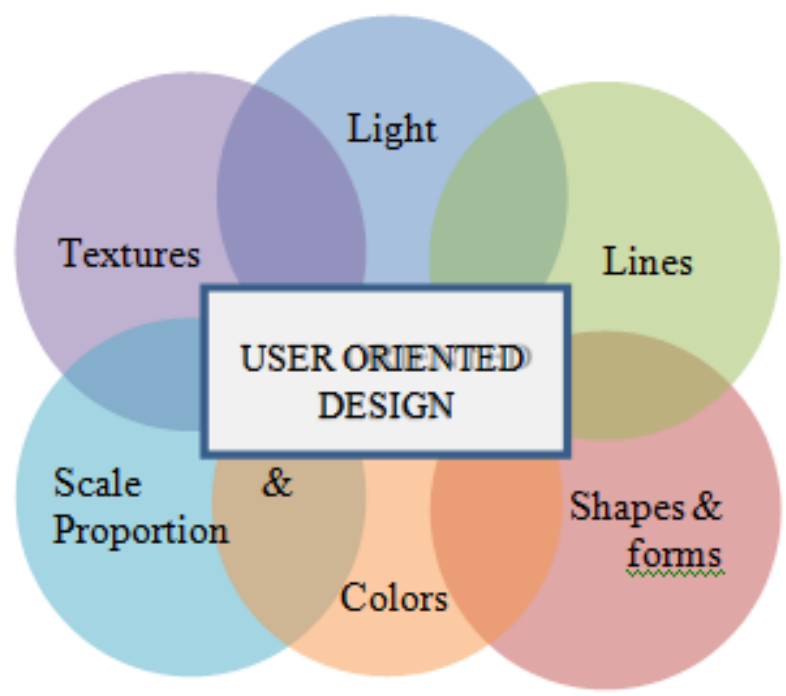

\section{CASE STUDIES}

Two secondary case studies, Tara housing, and Studios 18 apartments have been selected based on various design aspects like colors, lighting, material, segregation of spaces, built-open relationship, etc. 


\section{International Journal of Social Science and Economic Research}

ISSN: 2455-8834

Volume:06, Issue:06 "June 2021"

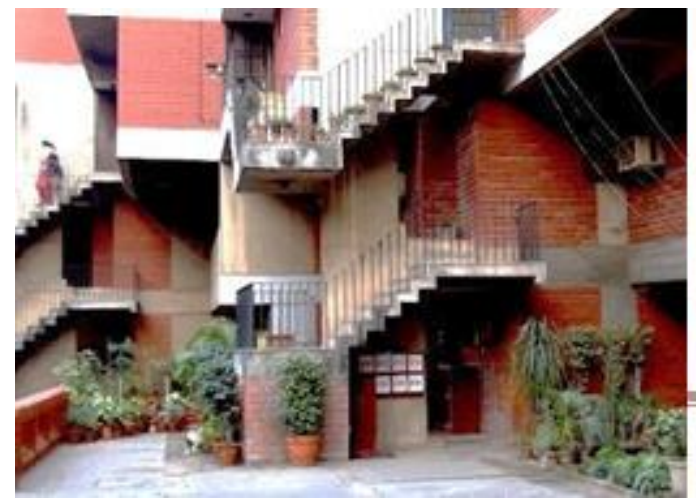

Figure 9 Tara Housing

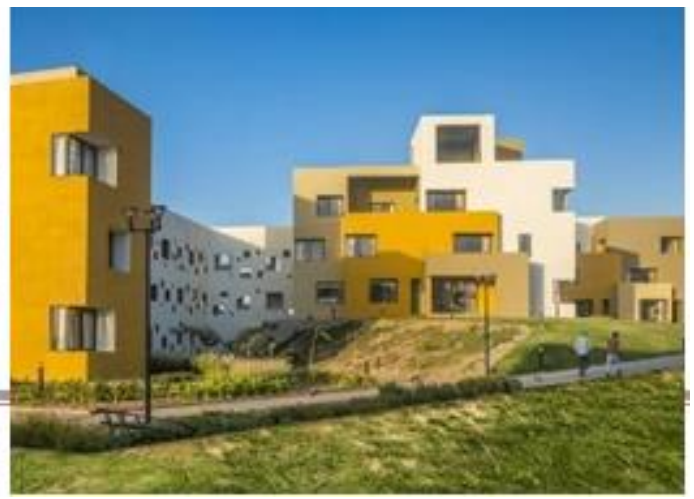

Figure 10 Studio 18 Apts.

\subsection{Tara Housing Apartments}

Tara housing society is a middle-class housing complex designed by Charles Correa that reflects theIndian vernacular form of the 1970s.

Various spaces in the housing complex are divided into community space, dwelling units, and parking spaces, creating a balance of built and open spaces.

Built spaces constitute $30 \%$ of the ground cover that evoke emotions of contentment and safety andthe open spaces create a sense of freedom. This balance between built and open spaces is also maintained at the unit level by creating double-height terraces and verandas.

The plan of the complex is a simple rectangular shape, replicated and staggeringly placed in 2 rows,creating interesting spaces and breaking the monotony.

In form, a cuboidal unit has been placed one over another, in a similar staggered manner, breaking the verticality of the built form and creating horizontal bands on all floor levels, which gives a feeling of majesties yet comfortable to the human scale.

Public and private spaces are segregated in the complex, and introvert planning is followed. All the homes are facing a central garden, which induces emotions like freedom, safety, and calmness.

The unit plan, social and personal spaces are provided on the ground floor and intimate spaces on the first floor. This allows privacy in the unit. The rooms are rectangular which creates a sense of stabilityand assurance.

The built open ratio is almost 1:1. Double height terraces create a sense of enthusiasm and connectionwith nature. 
International Journal of Social Science and Economic Research

ISSN: 2455-8834

Volume:06, Issue:06 "June 2021"

Central garden and recessed floors allow infiltration of ample light within the units, which improve cognitive functioning and overall mental and physical health of the residents.

\subsection{Studio 18 Apartments}

Studios $18 \mathrm{~m}$ is a contextually designed housing project for the workers of a cement factory that had commenced work nearby. Designed by Sanjay Puri Architects, it is located in Rajasthan with an area of 1.21 acres having 18 units of 2 and 3 bedrooms. The concept was emulating the organically laid out villages from the surrounding area.

The built and open spaces create a sense of comfort for the residents and the visitors as well. The repeating geometric units that are placed along a staggering path create a variety of different spacesthus inducing excitement among the residents. Each of these units are oriented differently for a unique and riveting view.

The main and basic form of the building is three stories tall with just one unit on each floor. Each of these units have cut outs on the ceilings which create interesting shadows during the daytime so occupants may feel stimulated and lively.

The building apartments are separate private spaces where residents feel peaceful and relaxing while the corridor spaces are the semi-private spaces. Their staggering nature creates a sense of surprise and is very soothing due to the colours of the corridor. The open public spaces are very vast and tranquil that are undisturbed.

Cubes and cuboids are the main shapes that are followed in the project in the form of the units as well as the cut outs, which create a harmony in the whole site.

The corridors are naturally ventilated because of this abstract composition of cut outs- thus allowingin natural light in these long and linear spaces.

Colour plays a very important role in this project and it emulates the colour scheme that we see in the surrounding areas of Rajasthan. The lighter hues on the external walls reflect heat thus making the residents feel comfortable inside and the corridor interiors are painted in darker hues to create a cooler effect.

\section{Survey}

\subsection{Survey Conclusion}

A survey was conducted of about 225 people, the majority of them are between the ages of 16-25 years old $(89.7 \%)$, with $67.1 \%$ being females. $54.3 \%$ of people live in plotted housing while the 


\section{International Journal of Social Science and Economic Research}

ISSN: $2455-8834$

Volume:06, Issue:06 "June 2021"

restreside in apartments/ group housing; with a majority of the people, $81.2 \%$ being the owners of theirhomes.

$52.5 \%$ of people feel the most connected to their homes and maximum people felt happy and contented after reading the following statement:

"A home is not a mere transient shelter: Its essence lies in the personalities of the people who live in it, which makes it different from a house"

Coming inside the homes, the majority of people felt most connected to their bedrooms, the reason for which we can infer from our literature studies as this space being the most personal to people.

We also found $14.2 \%$ of people feeling most attached to their terraces/ balconies/ verandas, the reason for which can be inferred as people liking open spaces especially feeling the importance of such spaces during the current pandemic.

When asked about their preference between studio apartment and traditional allocation of functionsin different spaces, about $75 \%$ of the people responded with preferring the latter.

According to our literature studies, the type and amount of lighting play an important role in how a person might feel inside a given space in their homes. This point is also reinforced in the survey conducted, with $88.8 \%$ of people saying that lighting does affect their mood. Now we need to define the type of lighting that is preferred- $92.8 \%$ of people favor natural lighting in their homes. And $53 \%$ of people preferred wide windows.

Every color instils a different feeling in different people, and in our survey, we tried to find the same. Most people feel "happy" seeing yellow, purple, blue, green color, we did get other responses for a few colors as well: Red: angry; Green, blue, white: calm; Black: Neutral. Delving further into the connection between colors, emotions, and homes, we got various responses. The majority of people want neutral colors in all spaces of their homes, except in the living room, where people prefer contrasting colors. A lot of people prefer cool colors in their study rooms whereas warm colors in their prayer rooms. In the bathrooms, many people also like monochromes and cool-toned colors. Instead of monochrome painted staircases, people want them to be interesting with a play of contrasting colors and natural lighting.

\section{Conclusion of the study}

The conclusion we were able to draw from our study was that not only emotions and architecture are correlated but can also be a design strategy to work with. Different design aspects are responsible for generating different emotions subconsciously. The most crucial deciding factors 


\section{International Journal of Social Science and Economic Research}

ISSN: $2455-8834$

Volume:06, Issue:06 "June 2021"

being from lighting followed by material, scale, and texture, etc. These aspects and spaces are defined in a functional boundary to create a different atmosphere for each space, catering to the emotional needs of all the occupants differently.

Example: Kids' play area may need bright colors with tactile textures to bring forth emotions of joy and fascination whereas a study room with neutral colors and smoothtextures for a calm and intimate feeling.

Our homes have a massive impact on our emotions - lights can amplify our emotions, colors can change our mood, elements in our design can make us feel safer and the texturecan impact our feelings. Open spaces like verandas and balconies in a residence act as a psychological vent.

To be able to design atmospheres attuned to the concerns of the user a new kind of designprocess is needed. Different users have different perceptions.

Example: Terrace of housing might be comforting for one but fearful for other

Although each of the emotions can be elicited by architecture, it is unclear to what extentthey all can represent unique emotions.

\section{References}

- Ab. Aziz, S. and Olalere F.E. 2013, Enhancing well-being through emotional and spiritualcontents of spaces, $2^{\text {nd }}$ Southeast Asian Housing Forum, Johor Bahru. Malaysia

- Amira Mersal, The impact of built environment on human behaviours Amira Mersal

- Armando Jose Uhia Hernandez 2017, Architecture and Emotion, Dealing the relationship in between Spatial Composition and Sensory Reactions, The Leeds School of ArchitectureLeeds Beckett University

- AvishagSjemesh, Moshe Bar, Yasha Jacob Grobman 2015, Space and Human Perception -Exploring Our Reaction to Different Geometries of Spaces, Faculty of Architecture and Town Planning, Technion - Israel Institute of Technology, Haifa, Israel

- G Brown, J Pickerill 2009, Emotion, Space and Society: Space for emotion in the spaces ofactivism.

- Hilde Heynen 2013, Space as Receptors, Intrument or Stage: Notes on interaction between Spatial and Social Constellations, Department of Architecture, University of Leuven, Belgium 


\section{International Journal of Social Science and Economic Research}

ISSN: 2455-8834

Volume:06, Issue:06 "June 2021"

- Kurt Dietrich, Architectural Design Elements

- Lindsay Charnofsky 2012, The interrelationship between Human Behavior and Sustainability in the Built Environment, Kent State University

- MargritPernau 2014, Space and Emotion: Building to Feel.

- Michael Murphy, Architecture that's built to heal, ted talks

- Myung Eun Cho \& Mi Jeong Kim 2018, Measurement of User Emotion and Experience inInteraction with Space, Journal of Asian Architecture and Building Engineering

- Sana Malik, The Dynamics of Psychological Approach in Designing spaces

- SanyamBahga, An account of critical regionalism in diverse building types in postcolonialIndian architecture

- Sherine Fathy Alagamy, Khalid Al-Hagla, YousryAnany 2019, An Integrated Approach for AnalyzingConnectivityin Atria, Department of Architecture, Faculty of Engineering, Alexandria University, Egypt

- Simon Droog and Paul de Vries Explorelab 2009, Emotion in architecture; the experience of the user, Faculty of Architecture TU Delft

- Steen Eller Rasmussen 1959, Experiencing Architecture

- TallaHamdyMohmous, Interior architectural elements that affect human psychology and behaviour. 